\title{
Sciendo
}

\section{Relationship among Adolescents' Characteristics, Peer Group Influence and Anti-Social Behaviour}

\author{
A. Onoyase, Ph.D \\ E. E. Ebenuwa-Okoh, Ph.D \\ Department of Guidance and Counselling, \\ Delta State University, Abraka
}

Doi: 10.2478/jesr-2018-0026

\begin{abstract}
This study examined the relationship among Adolescents' developmental characteristics, peer group influence and their anti-social behaviours. Four research questions and four null hypotheses guided the study. The study is a survey -research. The sample size for this study is 594 students. The respondents were randomly selected from secondary schools in the 3 Senatorial Districts of Delta State. Questionnaire titled 'Relationship among Adolescents' Characteristics, Peer Group Influence and their Anti-social Behaviours" was used for this study. It has face and content validity. The reliability indices for the subgroups are as follows: physical characteristics, 0.68, intellectual characteristics, 0.68, social/ emotional characteristics, 0.70 , peer group influence, 0.71 and adolescents' anti-social behaviours, 0.69 . Regression and descriptive statistics were used to analyse the data. The findings revealed that physical, intellectual, social/emotional characteristics and peer group influence adolescents' anti-social behaviours. It was recommended that adolescents should be made to indulge in productive leisure time activities where they can dissipate their energies.
\end{abstract}

Keywords: Relationship, Adolescents, Characteristics, Peer Group, Influence, Anti-Social, Behaviour

\section{Introduction}

Indisputably the youths of any country are a great force to reckon with if their development is of great priority to the government. If individuals who are virile and energetic are well channeled, there will be tremendous transformation and such a nation will develop optimally. According to EbenuwaOkoh, Akpochafo and Onoyase (2014), when such energies are dissipated on activities that are inimical to national development, such a country will certainly witness serious problems. As matter of fact, this is what Nigeria is experiencing presently. To be precise, the youths referred to in this study are the adolescents. It is no longer news that many adolescents are engaged in anti-social behaviours which are manifested in the form of rape, sexual promiscuity, disobedience to constituted authority, examination malpractice, forgery, abortion, truancy, stealing, robbery, kidnapping and riots. Commenting on this, Gerry-Eze and Eze (2006) opined that anti-social acts or deviant behaviour among adolescents are behaviours that are contrary to socially accepted moral behaviour and that these include cheating in examination, vandalism, drug abuse, smoking, aggression, bullying, lateness to school and so on and so forth.

Deviant behaviour among adolescents is not new in Nigeria. The phenomenon has been there since time immemorial and there were different ways communities meted out punishment to offending youths. According to Okobiah (2014), every community had its own values, norms, accepted and unacceptable behaviours and that such values and norms were observed by all. 
Continuing, she reiterated that there were traditional courts where deviants (including adolescents) were tried and punished. These practices, whereby deviant behaviours were corrected have gradually faded away from the society.

Today, the incidence of anti-social behaviours seems to be on the increase in Nigeria. This may be attributed to educational and technological advancement, civilization and urbanization which have made youths to regard their culture as inferior to Western culture. Additionally, the Mass Media and most recently, the Information Communication Technology, (ICT) have exposed adolescents to pornographic literature which now increases their sexual urge greatly. The developmental characteristics of the adolescents have been linked to anti-social behaviour among them (Ebenuwa-Okoh, Akpochafo and Onoyase, 2014).

\subsection{Physical Characteristics of Adolescents}

Adolescence is the period between childhood and adulthood and it is the stage of life from puberty to adulthood and the age bracket is between 11-20 years. According to the Free Dictionary, adolescence is a period of physical and psychological development from the onset of puberty to maturity. Actually, this is a phase of life when the adolescent experiences remarkable physiological changes which include the development of secondary sex characteristics, growth spurt and hormonal changes. Akanle and Odu (2004) classified changes in hormonal level to include acceleration and sometimes decrease in skeletal and muscular growth, changes in body composition due to hormonal and fat deposition, accelerated development of the circulatory and respiratory systems. Other changes according to the authors are development of the reproductive organs and development in the capacity of the activities of hormones and the brain.

There is no gainsaying the fact that these physical features influence the behaviour of adolescents to a large extent. Buttressing this fact; Akanle and Odu (2004) opined that the rapid growth results into restlessness and fatigue for the adolescent. Turner (1995) pointed out that teenagers are aroused sexually and that in trying to satisfy such urge, may commit rape (or incest if such sexual acts are carried with family members). Still on the challenges adolescents face as a result of physical development, Bamgbaye (1979) as cited in Mburza (2006) stated that sex interest in adolescents is manifested in their preference for nude pictures, exhibition of body parts and acts of masturbation. Okpako (2009), Ezeh (2005) \& Wu, Chia, Lee Shin Yng and Lee Yuch Wun (1998) reiterated that biological changes in adolescents is a driving force behind all their behaviours. They noted that as adolescents grow older, they are more attracted to participate in deviant behaviour. This implies that they become more courageous to try out new things, more criminally minded and rebellious in nature. It was found that mean scores for the 15 years of age was significantly higher than other years (Wu et al, 1998).

\subsection{Intellectual Characteristics of Adolescents}

Cognitively, the adolescent period coincides with Jean Piaget (1952) Formal Operational stage and is marked by abstract thinking, inductive and deductive reasoning and high level of imagination. Akinboye (2000) as cited in Akanle and Odu (2004), emphasized that youths become very rebellious, outright and disobedient at this stage. From observation, the researchers have also noticed other intellectual characteristics of youths at this period and they include enjoying intellectual activities, high level of curiosity, imagining things and sometimes living in a world of their own even in the midst of others. Parent Tip Sheet I (2009) noted that adolescents possess increased communication skills, become argumentative and want to be proved right at all times. Adolescents' arguments to convince adults of their points may be regarded as rudeness and disrespect to elders. This is a deviation from accepted norms of the African society.

\subsection{Social/ Emotional Characteristics of Adolescents}

Socially, adolescence period fits into the fifth stage of Sigmund Freud (1908) theory of personality development and it is the Genital stage (i.e. puberty to adulthood). At this stage, there is a shift from 
homosexual relationship to heterosexual interaction and there is great admiration for members of the opposite sex. According to Parent - Sheet 1 (2009), teenagers show strong desire for independence and autonomy. In Eric Erikson (1950) psycho-social theory of personal development, adolescence period falls within the fifth stage of identify versus role confusion. Here, the adolescent is expected to know what the society expects from him, the type of personality and self-concept he has to carve out for himself and if these are achieved, then he develops a healthy personality. If the contrary is the case, he experiences role confusion. Mburza (2006) asserted that adolescents are becoming more independent of their parents and also free from parental supervision earlier than before. And because of their desire for independence, they get involved in anti-social behaviour just to prove they are matured. In the view of Akinboye (2000) as cited in Akanle and Odu (2006), nearly all adolescents' problems (such as sex behaviour, school related, family oriented, developmental, delinquent and moral behaviours) may be traced to the high rate of development taking place at physical, social as well as behavioural levels.

From experience as parents and teachers, these writers have observed that there is great instability in the mood of adolescents and in addition, they exhibit temper tantrums like infants. Supporting this view, Newsweek (2004) described adolescents as being impatient, insecure and overly emotional. This instability in emotion makes them to indulge in unacceptable behaviour.

\subsection{Peer Group Influence}

Undoubtedly, friends play a significant role in the lives of adolescents. At this phase of their lives, peers' advice tend to replace that of parents and this is why some of them have serious disagreement with their parents or guardians. According to Okafor and Nnoli (2010), adolescents create a separate world for themselves using slangs, coded language, facial expression, body language which can only be understood by their peers. They also rely completely on peers' counsel and regard their parents as "old school" or "old fashioned". Obviously, the peer-group can be positive and helpful such as helping themselves develop new skills or stimulate interest in books, music or extracurricular activities. Contrariwise, friends may have bad influence on adolescents and these may include skipping classes, stealing, cheating in examination, drug abuse and in indulging in risky sexual activities.

In the words of Onohwosafe (2013), other risky behaviour of adolescents are poor eating habits, high level of anxiety, emotional and behavioural problems and stress disorder. Generally, the effects of negative peer pressure on adolescents may be numerous and these could include alienation from the family, disobedience and total disregard for the opinions and values of their parents. If these problems are not properly handled, they may result to behavioural and psychological disorder. What then is the relationship among adolescents' characteristics, peer group and their anti-social behaviours?

\subsection{Purpose of the Study}

The purpose of the study is to determine the relationship among adolescents' characteristics, peer group and their anti-social behaviour in senior secondary schools, Delta State, Nigeria.

\subsection{Research Questions}

The following questions were raised to guide the study:

1. What is the relationship between physical characteristics of adolescents and their antisocial behaviours?

2. What is the relationship between intellectual characteristics of adolescents and their antisocial behaviours?

3. What is the relationship between social/ emotional characteristics of adolescents and their anti-social behaviours?

4. What is the relationship between peer group influence and adolescents' anti-social behaviours? 
5. What are the composite relationship among physical characteristics, intellectual characteristics, social/emotional characteristics, peer .group influence and adolescents' anti-social behaviours?

\subsection{Hypotheses}

The following hypotheses were generated to guide the study:

- Ho : There is no significant relationship between physical characteristics of adolescents and their anti-social behaviour.

- $\quad \mathrm{Ho}^{2}$ : There is no significant relationship between Intellectual characteristics of adolescents and their anti-social behaviour.

- $\mathrm{Ho}^{3}$ : There is no significant relationship between social/emotional characteristics of adolescents and their anti-social behaviour

- $\mathrm{Ho}^{4}$ : There is no significant relationship between peer group influence and adolescents' anti-social behaviour.

- Ho5: There is no significant relationship among physical characteristics, intellectual characteristics, social/emotional characteristics, peer group influence and adolescents', anti-social behaviour?

\section{Method}

Design: This study is a survey. It adopted Ex-post-facto research. It examined the relationship among adolescents' developmental characteristics and their anti-social behaviours. The target population was all Senior secondary School Two and Three students (SS II and SS III). Multi-Stage random sampling procedure was used to select the sample size of 594 students from the three Senatorial Districts of Delta State. Four local government areas were randomly selected from each Senatorial District and a town each was selected from each of the selected local government areas.

Two schools were selected from the respective towns representing private and public schools; in each school, equal number of SSI and SSII students who were selected responded to the questionnaire. The instrument for this study was a questionnaire titled "Relationship among adolescents' characteristics, peer group and their anti-social behaviours." The questionnaire is in two parts; Section A described the biodata of the respondents which include: gender, type of school, number of children in family, types of family and class level. The section B described different developmental characteristics of adolescents which were physical characteristics, intellectual characteristics, social/ emotional characteristics and peer group influence.

The physical characteristics consists of the following items: the development of secondary sex characteristics increase my sexual urge, I am very conscious of my body image, hormonal changes affect my mood, rapid growth makes me eat more. Intellectual characteristics items are: I enjoy intellectual activities, I question existing rules, I want to know everything about my environment. Social/ Emotional characteristics items are: My desire for people to accept me has increased, I like to be current (in music, fashion and speech). I am always happy whenever sexual issues are discussed. Peer group influence items are: My friends influence the way I dress, my friends influence the way I prepare for examination, my friends influence the way I behave in class. Adolescent anti-social behaviour items are: I enjoy breaking rules, I like to ask adults questions concerning the way I think, I hate to be criticized, I do not like to be supervised by adults.

Each of the above characteristics has five items while the adolescents' anti-social behaviour has ten (10) items. The instrument has face and content validity. The reliability indexes for the subgroups in the instrument were obtained using Cronbach Alpha procedure; physical characteristics, $r=0.68$, intellectual characteristics $r=0.68$ social/emotional $r=0.70$, peer group influence $r=0.71$, and adolescents' anti-social behaviour $r=0.69$. Descriptive and regression statistical tools were used to analyze the data. 


\section{Presentation of Findings}

Table 1: Mean, Standard deviation, correlation matrix between Adolescents' Characteristics, peer group influence and their Anti-social behaviour.

\begin{tabular}{|c|c|c|c|c|c|c|}
\hline Variables & Mean SD & $\begin{array}{l}\text { Anti-social } \\
\text { behavior }\end{array}$ & $\begin{array}{c}\text { Physical } \\
\text { characteristics }\end{array}$ & $\begin{array}{c}\text { Intellectual } \\
\text { characteristics }\end{array}$ & $\begin{array}{l}\text { Social/ emotional } \\
\text { characteristic }\end{array}$ & $\begin{array}{c}\text { Peer } \\
\text { influence }\end{array}$ \\
\hline Adolescent anti-social behavior & 25.594 .60 & 1 & & & & \\
\hline Physical & 13.762 .63 & $.230^{*}$ & 1 & & & \\
\hline Intellectual & 16.302 .60 & $.225^{\star}$ & $.176^{*}$ & 1 & & \\
\hline Social/ emotional & 14.272 .72 & $.256^{*}$ & .323 & .194 & 1 & \\
\hline Peer influence & 13.293 .33 & $.156^{*}$ & .041 & $.114^{*}$ & $.138^{*}$ & 1 \\
\hline
\end{tabular}

Table 1 shows that physical characteristics of adolescents has significant relationship with their Anti-social behaviour. The correlation matrix reveals that significant relationship exists between physical characteristics and anti-social behaviour yielding $r=.230, P>0.05$ with the mean score of 13.76 and standard deviation of 2.63 while the relationship between intellectual characteristics and anti-social behaviour of respondents was $0.225, \mathrm{P}>0.05$ with a mean score of 16.30 and standard deviation of 2.60. However the relationship between social/emotional characteristics and Anti-social behaviour of the respondents was 0.256 with mean score of 14.72 and standard deviation of 2.72. Also peer group was related to the respondents anti-social behaviour with $r=.16$ with mean score 13.29 and standard deviation of 3.33. All the independent variables were significantly related to the dependent variable at 0.05 level.

\subsection{Research Question One}

\subsubsection{Hypothesis One}

There is no significant relationship between physical characteristics and Adolescents' Anti-social Behaviours.

To test this hypothesis, a simple linear regression was conducted with adolesents' anti-social behaviour as the dependent variable and the scores for physical characteristic of the students as Independent variable. The summary of the result is given in table 1 below.

Table 2: Regression output of physical characteristics and anti-social behaviour

\begin{tabular}{|l|c|c|c|c|c|c|c|}
\hline Variable & $\mathbf{F}$ & $\mathbf{R}$ & $\mathbf{R}^{2}$ & Adj. $^{2}$ & $\boldsymbol{\beta}$ & $\mathbf{t}$ & $\mathbf{P}$ \\
& 48.45 & 0.28 & 0.08 & 0.07 & & & 0.00 \\
& \multicolumn{7}{c}{ Variables in the equation } \\
& $\mathrm{B}$ & & & & & \\
& \multicolumn{2}{c}{ SEB } & & & & \\
Physical characteristics & 0.48 & 0.07 & & 0.28 & 6.96 & 0.00 \\
Constant & 18.97 & 0.97 & & & 19.61 & 0.00 \\
\hline
\end{tabular}

df (1.592), $P \leq 0.05$ level of significance

Table 2 shows that there is a significant relationship between Physical characteristics and adolescents' anti-social behaviour as indicated by the $r$ value of 0.28 . There is a positive relationship between physical characteristics and adolescents anti-social behaviour. Also indicating a statistical significance in the regression model as indicated by $F(1.592)=48.45, P=0.00$. The Null hypothesis is therefore rejected. There is therefore a significant relationship between Physical Characteristics and Adolescents' Anti-social-Behaviour.

The adjusted $\left(R^{2}\right)$ value of 0.07 shows that only $7 \%$ of adolescents anti-social behaviour is due to the physical characteristics of the adolescents. 


\subsection{Research Question Two}

\subsubsection{Hypothesis Two}

There is no significant relationship between intellectual Characteristics and Adolescents Anti-social behaviour.

To test this hypothesis, a linear regression was conducted and the result is presented in table 3 .

Table 3: Regression output of intellectual characteristics and Adolescents' Anti-social behaviours.

\begin{tabular}{|c|c|c|c|c|c|c|c|}
\hline Variable & $\begin{array}{c}\mathbf{F} \\
57.54\end{array}$ & $\begin{array}{c}\mathbf{R} \\
0.38\end{array}$ & $\begin{array}{c}\mathbf{R}^{2} \\
0.09\end{array}$ & $\begin{array}{c}\text { Adj. } \mathbf{R}^{2} \\
0.09\end{array}$ & $\beta$ & $\mathbf{t}$ & $\begin{array}{c}\mathbf{P} \\
0.00\end{array}$ \\
\hline \multicolumn{8}{|c|}{ Variables in the equation } \\
\hline & B & & SEB & & & & \\
\hline intellectual characteristics & 0.53 & & 0.07 & & 0.30 & 7.59 & 0.00 \\
\hline Constant & 17.01 & & 1.15 & & & 14.85 & 0.00 \\
\hline
\end{tabular}

$\mathrm{df}(1.592), \mathrm{P} \leq 0.05$ level of significance

Table 3 shows that there is a significant relationship between Intellectual Characteristics and adolescents' anti-social behaviour as indicated by the $r$ value of 0.38 . Therefore, there is positive relationship between intellectual characteristics and adolescents' anti-social behaviour. There is a statistical significance in the regression model as indicated by $F(1,592)=57.54, P \leq 0.05$. The Null hypothesis is therefore rejected and the alternative holds true. There is therefore a significant relationship between intellectual characteristics and adolescents' antisocial behaviours.

The adjusted $\mathrm{R}^{2}$ value of 0.09 shows that only $9 \%$ of Adolescents' Anti-social behaviour is due to the intellectual Characteristics of the Adolescents.

\subsection{Research Question Three}

\subsubsection{Hypothesis Three}

There is no significant relationship between Social/ Emotional Characteristics and Adolescents' Anti-social Behaviour.

Linear Regression Analysis was used to test the Null Hypothesis Three. The summary of the result is presented in table 4 below.

Table 4: Regression output of Social/Emotional Characteristics and Adolescents' Anti-social Behaviour.

\begin{tabular}{|c|c|c|c|c|c|c|c|}
\hline Variable & $\begin{array}{c}\mathbf{F} \\
108.22\end{array}$ & $\begin{array}{c}\mathbf{R} \\
0.39\end{array}$ & $\begin{array}{c}\mathbf{R}^{2} \\
0.16\end{array}$ & $\begin{array}{c}\text { Adj. } \mathbf{R}^{2} \\
0.15\end{array}$ & $\beta$ & $t$ & $\begin{array}{c}\mathbf{P} \\
0.00\end{array}$ \\
\hline \multicolumn{8}{|c|}{ Variables in the equation } \\
\hline Social/ Emotional characteristics & 0.67 & & 0.06 & & 0.39 & 10.40 & 0.00 \\
\hline Constant & 16.10 & & 0.93 & & & 17.34 & 0.00 \\
\hline
\end{tabular}

Df (1.592), P $\leq 0.05$

Table 4 shows that there is a significant relationship between Social/Emotional Characteristics and adolescents' anti-social behaviour as indicated by the $r$ value of 0.39 and $p$ value of 0.00 . There is a positive relationship between social/ emotional characteristics and antisocial behaviour. Also indicating a statistical significance is the regression model as indicated by $F(1.592)=108.22$ and $p=0.00$. The Null hypothesis is therefore rejected and the alternative holds true. There is therefore a significant relationship between social/ emotional characteristics and adolescents' anti-social behaivour.

The adjusted $\mathrm{R}$ value of 0.15 shows that only $15 \%$ of Adolescents' Anti-social Behaviour is due to the social/emotional Characteristics of the Adolescents. The Beta weight of 0.39 and $p$ value of 0.00 shows that Social/ emotional characteristics of an adolescent is statistically significant, unique to the prediction of adolescents' antisocial behaviour. 


\subsection{Research Question Four}

\subsubsection{Hypothesis Four}

There is no significant relationship between Peer Group Influence and Adolescents' Anti-social Behaviour.

Hypothesis Four was tested using Linear Regression and the summary of the output is presented in table 5 below.

Table 5: Regression Output of Peer Group Influence and Adolescents' anti-social behaviour.

\begin{tabular}{|l|c|c|c|c|c|c|c|}
\hline Variable & $\mathbf{F}$ & $\mathbf{R}$ & $\mathbf{R}^{2}$ & Adj. $\mathbf{R}^{2}$ & $\boldsymbol{\beta}$ & $\mathbf{t}$ & $\mathbf{P}$ \\
& 42.80 & 0.26 & 0.07 & 0.07 & & & 0.00 \\
& \multicolumn{7}{c}{ Variables in the equation } \\
& $\mathrm{B}$ & \multicolumn{3}{c}{ SEB } & & & \\
Peer group influence characteristics & 0.36 & 0.06 & & & & \\
Constant & 20.83 & 0.26 & 6.54 & 0.00 \\
\hline
\end{tabular}

Df (1.592), $p \leq 0.05$

Table 5 shows that there is a significant relationship between peer group influence and adolescents' anti-social behaviour as indicated by the $r$ value of 0.26 and $p$ value of 0.00 . Therefore, there is a positive relationship between peer group influence and adolescents' anti-social behaviour. Also indicating a statistical significance is the regression model as indicated by $F(1,592)=42.80$ and $p=$ 0.00 . The Null hypothesis is therefore rejected and the alternative holds true. There is therefore a significant relationship between Peer Group Influence and Adolescents' Anti-social Behaviour.

The Adjusted $\mathrm{R}$ value of 0.07 shows that only, $7 \%$ of Adolescents' Anti-social Behaviour is due to the social/emotional Characteristics of the Adolescents. The Beta weight of 0.26 and $p$ value of 0.00 shows that Peer Group Influence makes a statistical significant contribution to the prediction of adolescents' anti-social behaviour.

\subsection{Research Question Five}

\subsubsection{Hypothesis Five}

What are the composite effects of peer-group influence, physical characteristics, social emotional characteristics, intellectual characteristics and adolescents' Anti-social behaviour?

Hypothesis Five states that there is no significant joint relationship between physical characteristics, intellectual characteristics, peer-group influence and Adolescents' anti-social behaviours.

Table 6: Multiple Regression Analysis of Adolescents' anti-social behaviour and Peer Group Influence, Physical Characteristics intellectual Characteristics, Social/Emotional Characteristics.

\begin{tabular}{|c|c|c|c|c|c|c|c|}
\hline \multirow[t]{3}{*}{ Variable } & $\begin{array}{c}\mathbf{F} \\
43.93\end{array}$ & $\begin{array}{c}\mathbf{R} \\
0.479\end{array}$ & $\begin{array}{c}\mathbf{R}^{\mathbf{2}} \\
0.230\end{array}$ & $\begin{array}{c}\text { Adj. } \mathbf{R}^{2} \\
0.225\end{array}$ & $\bar{\beta}$ & $\mathbf{T}$ & $\begin{array}{c}\mathbf{P} \\
0.00\end{array}$ \\
\hline & \multirow{2}{*}{\multicolumn{7}{|c|}{ Variables in the equation }} \\
\hline & & & SEB & & & & \\
\hline Peer group & 210 & & .052 & & .153 & 4.030 & .000 \\
\hline Physical characteristics & .227 & & .068 & & .130 & 3.346 & .001 \\
\hline Social / emotional characteristics & .422 & & .069 & & .250 & 6.098 & .001 \\
\hline Intellectual characteristics & .335 & & .067 & & .189 & 4.980 & .001 \\
\hline Constant & 8.190 & & 1.383 & & & & \\
\hline
\end{tabular}

Df (1.592), $p \leq 0.05$ level of significance. 
From the results presented in table 5 , the independent variable collectively yielded a co-efficient of multiple regression of $(R)$ of $.479, R^{2}$ of .230 and are adjusted $R^{2}$ of .225 . This shows that $23 \%$ of the total variance of Adolescents' anti-social behaviour of the participants is accounted for by the combination of the four predictive variables studied. The analysis of variance produced an F-ratio value significant at 0.05 level (43.93); $(P<0.05)$. The findings confirm that the four variables are significant predictors of the criterion measure whether jointly or separately from the Beta and $t-$ values.

\section{Discussion of Findings}

The first finding indicates that there is a significant relationship between adolescents' physical characteristics and their anti-social behaviour. The plausible reason for the finding is because there is development of secondary sexual characteristics and hormonal changes which lead to increased sexual urge and excess energy that must be dissipated. All these crystallize to influence teenagers' behaviour. This agrees with Akanle and Odu (2004) who opined that rapid growth results to restlessness and fatigue for adolescents. Also, Turner (1995) pointed out that adolescents are aroused sexually and in trying to satisfy such, if not properly checked can lead to deviant sexual behaviour.

The second finding reveals that there is a significant relationship between adolescents' intellectual characteristics and their anti-social behaviour. This is due to the fact that at this age, the brains of adolescents have developed tremendously and they now engage in inductive and deductive reasoning. This is in line with Akinboye as cited in Akanle and Odu (2004) who emphasized that adolescents engage in high level of imagination which involves inductive and deductive reasoning.

The third finding of this study has shown that there is a significant relationship between adolescents' social/emotional characteristics and their anti-social behaviour. The reason that can be adduced for this result is that adolescents' development has made them to be more involved in relationship with their peers irrespective of gender. This finding corroborates with the fifth stage of the work of Eric Erikson (psycho-social theory of personality development) and Mburza (2006) who observed that adolescents move from dependence on parents to independence, autonomy and maturity and leads them to trying out some unacceptable behaviour patterns.

The fourth finding of the study attests that there is a significant relationship between peer group influence and adolescents' behaviour. Undoubtedly, friends of adolescents have a stronghold on their lives because of the search for autonomy and role identity. This agrees with Okafor and Nnoli (2010) who noted that adolescents create a separate world for themselves using slangs, coded language, facial expression and body language which can only be understood by them.

The final analysis of the relationship between the independent variables of (peer-group influence, physical characteristics, social/emotional characteristics, intellectual characteristics) and dependent variable of adolescents' anti-social behaviour reveals that they separately and jointly were significant predictors at 0.05 level. However the strongest relationship fused was between social/ emotional characteristics and Adolescents' anti-social behaviour (.393), followed by intellectual characteristics and Adolescent antisocial behaviour $(.38$,$) the physical characteristics$ and adolescents' anti-social behaviour 0.28 and finally peer group influence and adolescents' antisocial behaviour $(r=0.26)$.

\section{Conclusion}

The conclusion that can be drawn is that all the developmental processes (Physical characteristics, intellectual characteristics, social/ emotional characteristics) of adolescents influence their antisocial behaviour. Also peer group pressure influence anti-social behaviour among adolescents.

\section{Counselling Implications}

The implication is that all stakeholders (counselors, psychologists, social workers, parents, 
teachers) in the life of adolescents should appreciate these challenges that confront these individuals in trying to fulfil their developmental obligations.

\section{Recommendations}

Based on the findings, the following recommendations have been made:

1. There should be orientation programmes or workshop for parents and teachers on challenges that confront adolescents and how to assist them.

2. Adolescents should be made to be involved in productive leisure time activities by stockholders where they can dissipate their energies.

3. Sex education should be integrated into the secondary school curriculum so that adolescents will be provided with the knowledge of how to channel their sexual urges profitably.

4. Personal-social services should be provided by Guidance counselors in all secondary schools so that productive interpersonal relationship can be sustained.

\section{References}

Akanle, F. F. and Odu, B. K. (2004).Physical Characteristics as Determinants of Adolescents' Moral behaivour. A Case Study of Adolescents in Ekiti State. Secondary Schools, Nigeria. The Nigerian Journal of Guidance Counselling. 9(1): 194-25.

Akinboye, T. O. (2000), Adolescent Personal Data Inventory. Ibadan: University- of Ibadan Press.

Ebenuwa- Okoh, E. E., Akpochafo, G. O. and Onoyase, A. (2014). Undergraduates' Perceptions of causes of Youth Restiveness in Delta State of Nigeria. Journal of Education and Practice International Institute for Science, Technology and Education. Publisher, United States America (USA) 5(2):1S1-155.

Erikson, E.H. (1950). "Psycho-Social Theory of Personality Development" Childhood and Society (2d Ed.) New York: Norton 1963.

Ezeh, C. O. (2005). Adolescent Psychology. Enugu: Computer Edge Published.

Farlex (On-line). The Free Dictionary. http:/www.thefreedictionary.com/

Freud, S. (1908) Psycho-Sexual. "Psychosexual Theory of Personality Development http;www.simplypsychology.org/sigmundfreud.ht

Gerry-Eze, U. I. and Eze, G. I. (2006). The Maladaptive Behaviour of Nigerian Youths: causes, Consequences and the Way Forward for Sustainable Political Development, Nigeria; Counselling Proceedings (CASSON).

Mburza, A. (2006), Sexual Problems of Nigerian Adolescents and their Implication for Counselling. The Nigerian Journal of Guidance Counselling. 11(1): 70-75.

Newsweek (2004). "Youth: A Different Way of Healing" Newsweek, June 14 pg 41.

Okafor, P.N and Nnoli, I.M (2010). "Premarital Sex and Teenage Pregnancy among Adolescents and its Counselling Implications". The Lagos Counsellor. 3(1):109-119.

Okobiah, O. C. (2014), "Counselling Against Deviant Behaviour for National Development". Delta Journal of Guidance and Counselling. 1 (1): 1-9

Okpako, J.E.F. I.A., Bamgbose, O. and Morokola, O. A. (2004), Parenting the Nigerian Adolescents Towards Smooth Transition to Adulthood. Ibadan: Omoade Printing Press. Pp 275-288,

Onohwosafe, P.S. (2013). "The Challenges of Adolescents" Inappropriate Sex habits: health Education and Counselling Implications. Delta Journal of Guidance and Counselling. (1): 122-135.

Parent Tip Sheet I (2009). Retrieved by Saint Mary Press http:www.google.com.ng/

Piaget, J. (1952), The Origins of Intelligence in children. New York International Universities Press.

Turner, AD. (1995). Child Development: Tokyo: McGraw-Hill International Books Company.

Wu, Chia, Lee Shin Yng and Lee Yuch Wun: (1998), Factors Affecting Adolescent Delinquency in Singapore. www.3.ntu.edu.sg/nbs/sabre/working paper. 